\title{
Interactive comment on "Global whole-rock geochemical database compilation" by Matthew Gard et al.
}

\author{
Juan Carlos Afonso (Referee) \\ juan.afonso@mq.edu.au \\ Received and published: 29 May 2019
}

This compilation and associated database make up a fantastic contribution to the geoscience community. It should be useful for a wide range of researchers.

The manuscript is well-written and easy to follow. The csv files are clear and easy to download and manipulate. Besides the comments from the other reviewers, the only shortcoming I found at the moment is the lack of interrogation and/or manipulation tools. The authors clearly state that they are creating such tools in matlab, which is terrific, but I would have loved to have at least some basic interrogation codes with this publication! Maybe something the authors can work on for a final version?

Another comment is about the computed properties (Vp, RHP, density). The authors 
refer to other works in the text for the methods, which is fine, and then include some equations in Table 3. Can the authors say anything about the uncertainties associated with these estimates? or even better, provide any sort of validation of the predictions against real measurements? I guess that at least some of the samples that made it into the database/s have been characterized well enough to include measured density and perhaps ultrasonic measurements of $\mathrm{Vp}$ (?). Such a validation would be great for us readers/users. Perhaps this has been done in the cited works, and if so, all good. l'd then just mention it in the manuscript and give a brief summary to help the reader.

Overall, a really nice contribution. Well done and thanks for your efforts!

Interactive comment on Earth Syst. Sci. Data Discuss., https://doi.org/10.5194/essd-2019-50, 2019. 